\title{
Chronic mountain sickness in Chinese Han males who migrated to the Qinghai-Tibetan plateau: application and evaluation of diagnostic criteria for chronic mountain sickness
}

Chunhua Jiang ${ }^{1,2,3}$, Jian Chen ${ }^{1,2,3}$, Fuyu Liu ${ }^{2,3}$, Yongjun Luo ${ }^{2,3,4}$, Gang Xu ${ }^{2,3}$, Hai-Ying Shen ${ }^{5}$, Yuqi Gao 1,2,3 and Wenxiang Gao ${ }^{1,2,3^{*}}$

\begin{abstract}
Background: Chronic mountain sickness (CMS), originally characterized by excess hemoglobin ( $\mathrm{Hb})$, is currently diagnosed using score-based diagnostic criteria combined with excessive erythrocytosis and clinical symptoms. However, the current criteria have limited applicability. We applied these criteria to 1,029 Chinese Han males migrated to and have been stayed at the Qinghai-Tibet plateau (3,700-5,000 m) for 2-96 months to investigate the prevalence of CMS and its correlations with $\mathrm{Hb}$ concentration, altitude, and the length of residence.

Methods: Subjects were screened for CMS using the latest approved diagnostic criteria combined with excessive erythrocytosis and clinical symptoms. Hb concentrations were measured, and a cut-off point was determined with $k$-means clustering. Predisposing factors were evaluated with binary logistic analysis and curve fitting analysis.

Results: (1) The prevalence of CMS at the Qinghai-Tibetan plateau was 17.8\% (183/1029 subjects, with CMS score $\geq 6$, and $\mathrm{Hb} \geq 210 \mathrm{~g} / \mathrm{L}$ ), which is higher than that previously reported. (2) While individuals were identified into two $\mathrm{Hb}$ clusters with a cut-off point of $200 \mathrm{~g} / \mathrm{L}$, in the low-Hb cluster $(\mathrm{Hb}<200 \mathrm{~g} / \mathrm{L})$, the oxygen saturation remained stable as the $\mathrm{Hb}$ increased; in the high-Hb cluster $(\mathrm{Hb} \geq 200 \mathrm{~g} / \mathrm{L})$, the oxygen saturation decreased as the $\mathrm{Hb}$ increased. (3) Two critical factors associated with CMS development were residence at an altitude of 4,500 $\mathrm{m}$ and a 60-month length of residence.

Conclusions: Our presenting scoring system is more sensitive than previous diagnostic criteria and favors early screening and treatment of patients with CMS. Our finding suggests that an adjusted $\mathrm{Hb}$ threshold of $200 \mathrm{~g} / \mathrm{L}$ (instead of $210 \mathrm{~g} / \mathrm{L}$ ) is more adaptable in Han individuals at all altitudes. The weight of Hb level should score $\geq 6$ points using the CMS scoring system because of the pathophysiologic role of excessive erythrocytosis in patients with CMS. In addition, our data suggest the importance of early screening of CMS via regular medical examinations within the first 60 months of residence at high altitudes, especially $>4500 \mathrm{~m}$.
\end{abstract}

Keywords: Hemoglobin, Altitude, Chronic mountain sickness, Hypoxia, Diagnostic criteria

\footnotetext{
*Correspondence: winneygao@hotmail.com

'Department of Pathophysiology and High Altitude Physiology, College of

High Altitude Military Medicine, Third Military Medical University, 30

Gaotanyan Street, Shapingba District, Chongqing 400038, P.R. China

${ }^{2}$ Key Laboratory of High Altitude Medicine, Ministry of Education, Third

Military Medical University, 30 Gaotanyan Street, Shapingba District,

Chongqing 400038, P.R. China

Full list of author information is available at the end of the article
} 


\section{Background}

Chronic mountain sickness (CMS) was first described as "Monge's disease" by Carlos Monge in 1928 [1], which is characterized by excessive erythrocytosis with the typical symptoms of polycythemia, hypoxemia, breathlessness, palpitations, sleep disturbances, cyanosis, venous dilatation, headaches, tinnitus, and dizziness [2]. There are approximately 140 million people living at high altitudes $(>2,500 \mathrm{~m})[2]$ and exposed to the risk of CMS in the world. In the Qinghai-Tibetan plateau of China where the largest population lives at a high altitude worldwide, CMS has been certified as an occupational disease by the Ministry of Health of People's Republic of China. Patients with CMS lose their ability to adapt to hypoxia and thus are unable to remain stay or full-time work at high altitudes. Therefore, patients must be precisely diagnosed and properly treated as early as possible once the development of CMS initiated.

However, it has been controversial regarding the definition and diagnostic criteria of CMS during the past decades. One focus of this debate is the diagnostic setting of hemoglobin $(\mathrm{Hb})$ threshold for polycythemia. Polycythemia is essentially an adaptive response to longterm hypoxic exposure, making it difficult to be distinguished from a maladaptive response. So far, different $\mathrm{Hb}$ thresholds at high altitudes have been used by medical researchers from different groups and countries [3-8]. To unify the definition and diagnostic criteria of CMS, the Sixth World Congress on Mountain Medicine and High Altitude Physiology redefined CMS as excessive erythrocytosis $(\mathrm{Hb} \geq 190 \mathrm{~g} / \mathrm{L}$ in female patients; $\mathrm{Hb} \geq$ $210 \mathrm{~g} / \mathrm{L}$ in male patients), severe hypoxemia, and, in some cases, moderate to severe pulmonary hypertension [9], and a quantitative CMS diagnostic criterion - the CMS score, based on symptoms and the Hb concentration, was also proposed and approved by the International CMS Consensus Working Group [9].

While the CMS scoring system has been applied in a small number of studies to date [4-8], improvement and refinement for the criteria is still needed. For example, $\mathrm{Hb}$ thresholds of $200 \mathrm{~g} / \mathrm{L}$ [7,8] and $210 \mathrm{~g} / \mathrm{L}$ [4-6] have both been used in male patients. Also, with respect to the essential diagnostic criteria for CMS, whether a sole excessive $\mathrm{Hb}$ level, a sole CMS score of $\geq 6$, or both should be applied remains confused. For instance, in one study, subjects were grouped into those with polycythemia (with an increased $\mathrm{Hb}$ level) and those with a CMS score of $\geq 6$ [5]. In another study, subjects were grouped according to CMS scores of $\leq 4,5$ to 9 , or $\geq 10$ [10], which is in contrast to the grouping of $\leq 5,6$ to 10 , 10 to 14 , or $\geq 15$ recommended by the Consensus Statement [9]. Furthermore, some researchers believe that most of the CMS symptoms are also commonly shared with cardiac, pulmonary, and other diseases, which lead the scoring system less reflect maladaptation to high altitudes after long-term hypoxic exposure, but instead may reflect lung or cardiac malfunction. Therefore, laboratory indices, such as the $\mathrm{Hb}$ level, oxygen saturation, and carbon dioxide retention, have been suggested to be more appropriate for CMS scoring [11].

In the presenting cross sectional study, we investigated the prevalence of CMS in 1,029 Chinese Han individuals who migrated to the Qinghai-Tibetan plateau at an altitude of 3,700 to 5,000 $\mathrm{m}$ using the latest approved scoring system. In addition, we analyzed the cut-off point of $\mathrm{Hb}$ for CMS diagnosis using a data mining method and further discussed the impacts of altitude and length of residence on the prevalence of CMS.

\section{Methods}

\section{Ethics statement}

The current survey was approved by the Ethics Review Board of the Third Military Medical University, Chongqing, China. Separate written informed consent was obtained from all subjects. No health interventions involving the subjects were performed. All individual data were anonymized prior to analysis.

\section{Study population}

Men are reportedly more prone to CMS than are women $[12,13]$. To exclude a sex difference, we only recruited men in our study. In total, 1,029 male Han Chinese volunteers were recruited from the Qinghai-Tibetan plateau (elevation: 3,700-5,000 m). The study participants were born and previously lived in low-altitude areas, including the Anhui, Beijing, Gansu, Guizhou, Hebei, Henan, Heilongjian, Hubei, Hunan, Jilin, Jiangsu, Jiangxi, Liaoning, Ningxia, Qinghai, Shandong, Shanxi, Shaanxi, Sichuan, Xinjiang, and Chongqing provinces of China. The following basic information about the subjects was obtained using a questionnaire: age (24.08 \pm 5.66 years), height $(172.11 \pm 4.94 \mathrm{~cm})$, and weight $(63.72 \pm$ $7.81 \mathrm{~kg}$ ). All subjects had resided at a high altitude for 2 months -8 years before testing. Individuals with pulmonary or cardiac diseases were excluded. Acute mountain sickness (AMS) and other disease histories, as well as cigarette and alcohol use, were also recorded from the questionnaire. An individual who has consumed at least 100 cigarettes in life was defined a smoker, and who consumes at least $20 \mathrm{~g}$ of pure alcohol per day was defined a drinker.

\section{Measurement of $\mathrm{Hb}$, oxygen saturation, and heart rate}

The $\mathrm{Hb}$ concentration was determined by cyanide measurement of blood samples obtained from each subject. Each sample was tested in duplicate. Physical parameters were recorded in the sitting position between 9:00 am and 12:00 am. The finger blood oxygen saturation $\left(\mathrm{sO}_{2}\right)$ 
was measured in the second left finger using a handheld oximeter (TuffSat; GE Healthcare, London, England). The heart rate (HR) and pulse pressure were determined with an electronic sphygmomanometer (HEM-7112; Omron, Kyoto, Japan).

\section{CMS diagnosis and score calculation}

The CMS diagnosis and score calculation were based on published criteria [9]. Briefly, symptoms of breathlessness/ palpitations, sleep disturbances, cyanosis, venous dilatation, paresthesia, headache, and tinnitus were weighted (0-3 points) according to severity. The $\mathrm{Hb}$ concentration was weighted ( 0 or 3 points) with a cut-off of $210 \mathrm{~g} / \mathrm{L}$. The points for all symptoms and the Hb concentration were summed to yield the CMS score. The severity of CMS was defined as follows: absent, score of 0 to 5 ; mild, 6 to 10 ; moderate, 11 to 14 ; and severe, $\geq 15$ (the $\geq 15$-point score was based on the Consensus Statement). A subject was considered to have CMS only if the $\mathrm{Hb}$ concentration was $\geq 210 \mathrm{~g} / \mathrm{L}$ and the CMS score was $\geq 6$. A subject was considered not to have CMS if the $\mathrm{Hb}$ concentration was $<210 \mathrm{~g} / \mathrm{L}$ or the CMS score was $<6$.

\section{Predisposing factors for CMS}

Various predisposing factors for CMS have been previously studied, including altitude, sex, age, ethnicity, length of residence, geographic factors, and cigarette smoking [14-16]. Since only Han males residing at the QinghaiTibetan plateau were tested in the current study, thus the influences of sex, ethnicity, and geographic factors were exclude. However, the factor of alcohol drinking was not excluded due to it is commonly performed in Han populations at high altitudes. To explore possible predictive parameters for diagnosis, we selected physiological indices, including the $\mathrm{sO}_{2}, \mathrm{HR}$, body mass index (BMI), and mean blood pressure, which have been proven to be affected by long-term hypoxic exposure. Because CMS symptoms are somewhat nonspecific, we included in the analysis a history of AMS, arthritis, stomach ulceration, cough, headache, cervical osteoarthritis, and other conditions. We pooled all other disease histories and grouped the subjects for comparison with subjects with no disease history because the sample number was not sufficiently large.

\section{Statistical analysis}

We compared the CMS prevalences (\%) with the $\chi^{2}$ test and the means of two different groups with the independent $t$-test. Data clusters were determined using the $k$-means clustering method. Pearson and Spearman coefficients were used to test bivariate correlations. Curve regression was also performed. The risk of CMS associated with each characteristic was tested by using a two- sided full model logistic regression analysis. All factors were firstly tested for bivariate correlations. Because the age and length of exposure to a high altitude were strongly correlated (data not shown), we omitted age and selected the length of exposure to a high altitude for the analysis. The independent variables which were entered into the final regression model included: altitude, $\mathrm{sO}_{2}$, drink, mean BP, BMI, altitude time, HR, AMS history, smoke, and disease history. A p value of $<0.05$ was considered to be statistically significant.

\section{Results}

\section{Prevalence of CMS}

Of the 1,029 subjects investigated, 183 (17.8\%) were diagnosed with CMS, including 101 (9.8\%) mild (CMS score of 6-10), 57 (5.5\%) moderate (CMS score of 11-14), and $25(2.4 \%)$ severe cases (CMS score of $\geq 15$ ). Notably, the $\mathrm{Hb}$ concentrations and CMS symptoms sometimes deviated from each other. Among 782 subjects with low $\mathrm{Hb}$ concentrations $(\mathrm{Hb}<210 \mathrm{~g} / \mathrm{L}), 214$ had a CMS score of 6 to 10,36 had a CMS score of 11 to 14 , and 11 had a CMS score of $\geq 15$ (Table 1 ).

\section{Correlations among $\mathrm{Hb}$ concentration, $\mathrm{sO}_{2}$, and symptoms}

The $\mathrm{Hb}$ concentration was significantly correlated with the $\mathrm{sO}_{2}$ (Pearson $=-0.121, \mathrm{p}=0.000$ ) (Table 2). Curve fitting analysis demonstrated that the best fitting curve was a quadratic curve $(\mathrm{F}=16.320, \mathrm{p}=0.000)$ (Table 2$)$, suggesting a two-phase $\mathrm{Hb}-\mathrm{SO}_{2}$ relationship according to the $\mathrm{Hb}$ value. We then classified the $\mathrm{Hb}$ concentration into two clusters using the $k$-means cluster method. The first cluster of $\mathrm{Hb}$ was $164.0-202.0 \mathrm{~g} / \mathrm{L}(185.57 \pm$ $10.64 \mathrm{~g} / \mathrm{L} ; 95 \% \mathrm{CI}, 200.5-203.4 \mathrm{~g} / \mathrm{L})$; the second cluster was $202.3-282.5 \mathrm{~g} / \mathrm{L}(218.68 \pm 14.27 \mathrm{~g} / \mathrm{L}$; 95\% CI, 203.4$251.3 \mathrm{~g} / \mathrm{L}$ ). Based on the above findings, we used $200 \mathrm{~g} / \mathrm{L}$ as the $\mathrm{Hb}$ cut-off point and divided the whole cohort into two clusters: the high $\mathrm{Hb}$ cluster $(\mathrm{HHbC})$, comprising subjects with an $\mathrm{Hb}$ concentration of $\geq 200 \mathrm{~g} / \mathrm{L}$, and the low $\mathrm{Hb}$ cluster ( $\mathrm{LHbC}$ ), comprising subjects with an $\mathrm{Hb}$ concentration of $<200 \mathrm{~g} / \mathrm{L}$. We demonstrated that the $\mathrm{Hb}$ concentration, CMS score, and altitude of residence were significantly higher in the $\mathrm{HHbC}$ than in the LHbC cluster $(p=0.000, p=0.000$, and $p=0.000$, respectively) (Figure 1E-G).

Next, we determined the correlations among the $\mathrm{Hb}$, $\mathrm{sO}_{2}$, and total symptom score (CMS score minus $\mathrm{Hb}$ score) in the two $\mathrm{Hb}$ clusters. In the $\mathrm{HHbC}, \mathrm{sO}_{2}$ was negatively correlated with $\mathrm{Hb}$ (Pearson $=-0.281, \mathrm{p}=0.000$ ), while the above two parameters were not significantly correlated in the LHbC (Pearson $=0.041, \mathrm{p}=0.338$ ) (Figure 1A); the mean $\mathrm{sO}_{2}$ value was significantly higher in the $\mathrm{LHbC}(88.89 \pm 8.37 \%)$ than in the HHbC (88.40 \pm $3.36 \%, p=0.036$ ) (Figure $1 \mathrm{~B}$ ). The total symptom score 
Table 1 CMS score summary

\begin{tabular}{|c|c|c|c|c|}
\hline & \multicolumn{4}{|c|}{ CMS score } \\
\hline & $<6$ & 6-10 & 11-14 & $\geq 15$ \\
\hline Prevalences $(n=1029)$ & 585 & 315 & 93 & 36 \\
\hline Percentage & $56.85 \%$ & $30.61 \%$ & $9.04 \%$ & $3.50 \%$ \\
\hline $\mathrm{Hb}$ Mean $\pm \mathrm{SD}(\mathrm{g} / \mathrm{L})$ & $191.00 \pm 15.01$ & $199.47 \pm 20.22$ & $210.41 \pm 22.64$ & $217.81 \pm 29.95$ \\
\hline $\mathrm{Hb}$ range (g/L) & $146.0-247.0$ & $153.5-269.0$ & $161.5-282.5$ & $167.5-267.5$ \\
\hline \multicolumn{5}{|l|}{$\mathrm{Hb}(\mathrm{g} / \mathrm{L})-\mathrm{no} .(\%)$} \\
\hline$<210(\mathrm{n}=782)$ & $521(66.62)$ & $214(27.37)$ & $36(4.60)$ & $11(1.41)$ \\
\hline$\geq 210(n=247)$ & $64(25.91)$ & $101(40.89)$ & $57(23.08)$ & $25(10.12)$ \\
\hline \multicolumn{5}{|c|}{ Breathlessness/Palpitations - no. (\%) } \\
\hline $0(n=442)$ & $376(85.07)$ & $55(12.44)$ & $10(2.26)$ & $1(0.23)$ \\
\hline $1(n=458)$ & $196(42.79)$ & $211(46.07)$ & $44(9.61)$ & $7(1.53)$ \\
\hline $2(n=114)$ & $13(11.40)$ & $46(40.35)$ & $37(32.46)$ & $18(15.79)$ \\
\hline $3(n=15)$ & $0(0.00)$ & $3(20.00)$ & $2(13.33)$ & $10(66.67)$ \\
\hline \multicolumn{5}{|l|}{ Sleep disturbance — no. (\%) } \\
\hline $0(n=467)$ & $400(85.65)$ & $56(11.99)$ & $11(2.36)$ & $0(0.00)$ \\
\hline $1(n=361)$ & $150(41.55)$ & $176(48.75)$ & $32(8.86)$ & $3(0.83)$ \\
\hline $2(n=166)$ & $33(19.88)$ & $76(45.78)$ & $39(23.49)$ & $18(10.84)$ \\
\hline $3(n=35)$ & $2(5.71)$ & $7(20.00)$ & $11(31.43)$ & $15(42.86)$ \\
\hline \multicolumn{5}{|l|}{ Cyanosis — no. (\%) } \\
\hline $0(n=441)$ & $384(87.07)$ & $54(12.24)$ & $2(0.45)$ & $1(0.23)$ \\
\hline $1(n=347)$ & $159(45.82)$ & $162(46.69)$ & $24(6.92)$ & $2(0.58)$ \\
\hline $2(n=160)$ & $31(19.38)$ & $71(44.38)$ & $46(28.75)$ & $12(7.50)$ \\
\hline $3(n=81)$ & $11(13.58)$ & $28(34.57)$ & $21(25.93)$ & $21(25.93)$ \\
\hline \multicolumn{5}{|l|}{ Dilatation of veins - no. (\%) } \\
\hline $0(n=793)$ & $548(69.10)$ & $212(26.73)$ & $28(3.53)$ & $5(0.63)$ \\
\hline $1(n=161)$ & $31(19.25)$ & $84(52.17)$ & $38(23.60)$ & $8(4.97)$ \\
\hline $2(n=58)$ & $5(8.62)$ & $15(25.86)$ & $22(37.93)$ & $16(27.59)$ \\
\hline $3(n=17)$ & $1(5.88)$ & $4(23.53)$ & $5(29.41)$ & $7(41.18)$ \\
\hline \multicolumn{5}{|l|}{ Paresthesia — no. (\%) } \\
\hline $0(n=518)$ & $446(86.10)$ & $69(13.32)$ & $2(0.39)$ & $1(0.19)$ \\
\hline $1(n=355)$ & 129 (36.34) & $178(50.14)$ & $44(12.39)$ & $4(1.13)$ \\
\hline $2(n=119)$ & $8(6.72)$ & $58(48.74)$ & $37(31.09)$ & $16(13.45)$ \\
\hline $3(n=37)$ & $2(5.41)$ & $10(27.03)$ & $10(27.03)$ & $15(40.54)$ \\
\hline \multicolumn{5}{|l|}{ Headache - no. (\%) } \\
\hline $0(n=435)$ & $382(87.82)$ & $50(11.49)$ & $3(0.69)$ & $0(0.00)$ \\
\hline $1(n=431)$ & $190(44.08)$ & $194(45.01)$ & $44(10.21)$ & $3(0.70)$ \\
\hline $2(n=130)$ & $13(10.00)$ & $65(50.00)$ & $34(26.15)$ & $18(13.85)$ \\
\hline $3(n=33)$ & $0(0.00)$ & $6(18.18)$ & $12(36.36)$ & $15(45.45)$ \\
\hline \multicolumn{5}{|l|}{ Tinnitus - no. (\%) } \\
\hline $0(n=596)$ & $482(80.87)$ & $101(16.95)$ & $12(2.01)$ & $1(0.17)$ \\
\hline $1(n=336)$ & $98(29.17)$ & $175(52.08)$ & $55(16.37)$ & $8(2.38)$ \\
\hline $2(n=77)$ & $5(6.49)$ & $33(42.86)$ & $23(29.87)$ & $16(20.78)$ \\
\hline $3(n=20)$ & $0(0.00)$ & $6(30.00)$ & $3(15.00)$ & $11(55.00)$ \\
\hline
\end{tabular}


Table 2 Correlation analysis model summary and parameter estimates of $\mathrm{Hb}$ with $\mathrm{sO}_{2}$

\begin{tabular}{|c|c|c|c|c|c|c|c|}
\hline & R Square & $\mathrm{F}$ & Sig. & Constant & b1 & b2 & b3 \\
\hline Linear & 0.015 & 13.218 & 0.000 & 92.878 & -0.021 & & \\
\hline Logarithmic & 0.012 & 10.883 & 0.001 & 109.176 & -3.880 & & \\
\hline Inverse & 0.010 & 8.760 & 0.003 & 85.163 & 689.842 & & \\
\hline Quadratic & 0.035 & 16.320 & 0.000 & 59.677 & 0.308 & -0.001 & \\
\hline Cubic & 0.035 & 16.300 & 0.000 & 71.091 & 0.141 & 0.000 & -0.000 \\
\hline Compound & 0.014 & 12.787 & 0.000 & 92.947 & 1.000 & & \\
\hline Power & 0.012 & 10.511 & 0.001 & 111.853 & -0.044 & & \\
\hline S & 0.009 & 8.446 & 0.004 & 4.444 & 7.832 & & \\
\hline Growth & 0.014 & 12.787 & 0.000 & 4.532 & -0.000 & & \\
\hline Exponential & 0.014 & 12.787 & 0.000 & 92.947 & -0.000 & & \\
\hline Logistic & 0.014 & 12.787 & 0.000 & 0.011 & 1.002 & & \\
\hline
\end{tabular}

Dependent variable: $\mathrm{sO}_{2}$; The independent variable is $\mathrm{Hb}$.

was significantly correlated with $\mathrm{Hb}$ in the $\mathrm{HHbC}$ (Spearman $=0.144, \mathrm{p}=0.000$ ) (Figure $1 \mathrm{C}$ ), but not in the LHbC (Spearman $=0.035, \mathrm{p}=0.993)$. The total symptom score was significantly lower in the LHbC than in the $\mathrm{HHbC}(\mathrm{p}=0.000)$ (Figure 1D).

\section{Predisposing factors for CMS}

We used binary logistic analysis to investigate CMS risk factors, including altitude, length of exposure to a high altitude, cigarette smoking, alcohol drinking, $\mathrm{sO}_{2}, \mathrm{HR}$, BMI, AMS history, other disease history, and mean blood pressure. The altitude, length of exposure to a high altitude, $\mathrm{sO}_{2}, \mathrm{HR}, \mathrm{BMI}$, alcohol consumption, AMS history, and mean blood pressure were significantly correlated with the prevalence of CMS $(p=0.000, p=0.021$, $\mathrm{p}=0.000, \mathrm{p}=0.023, \mathrm{p}=0.001, \mathrm{p}=0.000, \mathrm{p}=0.034$, and $\mathrm{p}=0.000$, respectively). However, cigarette smoking and a history of diseases other than AMS were not significant risk factors for CMS ( $\mathrm{p}=0.108$ and $\mathrm{p}=0.909$, respectively) (Table 3). Using these factors, we performed binary logistic analysis to derive an anticipation equation (Table 4) with which $93.38 \%$ of CMS-vulnerable and $37.60 \%$ of nonvulnerable persons can be anticipated (Table 5 ).

Because height and the duration of exposure to a high altitude were found to be correlated with the CMS score, we proceeded to cluster these two parameters with the $k$-means cluster method and found cut-offs of 4,500 m and 60 months, respectively. In the cluster of an altitude of $<4500 \mathrm{~m}$, the $\mathrm{Hb}$ concentration was not significantly correlated with the height $(\mathrm{F}=0.042, \mathrm{p}=0.836)$ with a relatively low mean $\mathrm{Hb}$ concentration $(192.5 \pm 1.72 \mathrm{~g} / \mathrm{L})$, while it was significantly correlated with height $(\mathrm{F}=$ $10.936, \mathrm{p}=0.001)$ in the cluster of an altitude of $\geq 4500 \mathrm{~m}$ with the mean value exceeded our cut-off point (207.4 \pm $21.8 \mathrm{~g} / \mathrm{L}$ ) (Figure 2A,B). In the cluster of an altitude time of $<60$ months, the $\mathrm{Hb}$ concentration was significantly correlated with the length of residence $(F=53.674$, $\mathrm{p}=0.000)$ with a low mean value, while it was not significantly correlated with the length of residence $(F=0.346$, $\mathrm{p}=0.557)$ in the cluster of an altitude of $\geq 60$ months with the mean value of $>200 \mathrm{~g} / \mathrm{L}$ (Figure 2C,D). Interestingly, there was a negative correlation between the CMS score and altitude in the $<4500-\mathrm{m}$ cluster $(\mathrm{F}=12.361$, $\mathrm{p}=0.000)$ and the mean CMS score remained $<6$ points. While the CMS score increased according to the altitude in the other cluster $(\mathrm{F}=10.816, \mathrm{p}=0.001)$ with a mean CMS score of about 8 (Figure 2E,F). On the other hand, the CMS score increased rapidly within 60 months after ascent to a high altitude $(\mathrm{F}=148.883, \mathrm{p}=0.000)$ and broke the 6-point threshold after approximately 2 years $(y=$ $0.1137 x+3.0812$ ) (Figure $2 G$ ). After 60 months, the mean CMS score exceeded 8 points and increased rather slowly as the exposure time was prolonged $(\mathrm{F}=7.446, \mathrm{p}=0.007)$ (Figure 2G,H).

\section{Discussion}

In past decades, thousands of patients with CMS have been investigated with a focus on the pathophysiologic mechanisms of this medical condition. Nevertheless, a number of questions remain to be elucidated. In the current study, we used the latest diagnostic criteria of CMS to evaluate 1,029 Chinese Han males who had been residing at Qinghai-Tibet plateau (3,700-5,000 m) for 2 months to 8 years. The prevalence of CMS in above population was $17.8 \%$ at 3,700 to $5,000 \mathrm{~m}$, which is higher than that of previous report with a prevalence of $11.83 \%$ at 4,006 to $5,226 \mathrm{~m}$ [17] at the QinghaiTibetan plateau. Our results using the latest diagnostic criteria suggest that present scoring system is more sensitive than previous diagnosis criteria, and favors early screening and treatment of patients with CMS. Our data demonstrate that $200 \mathrm{~g} / \mathrm{L}$ is the optimal for a cut-off point of $\mathrm{Hb}$ concentration in Han males residing at a high altitude though a cut-off of $\mathrm{Hb}$ concentration 


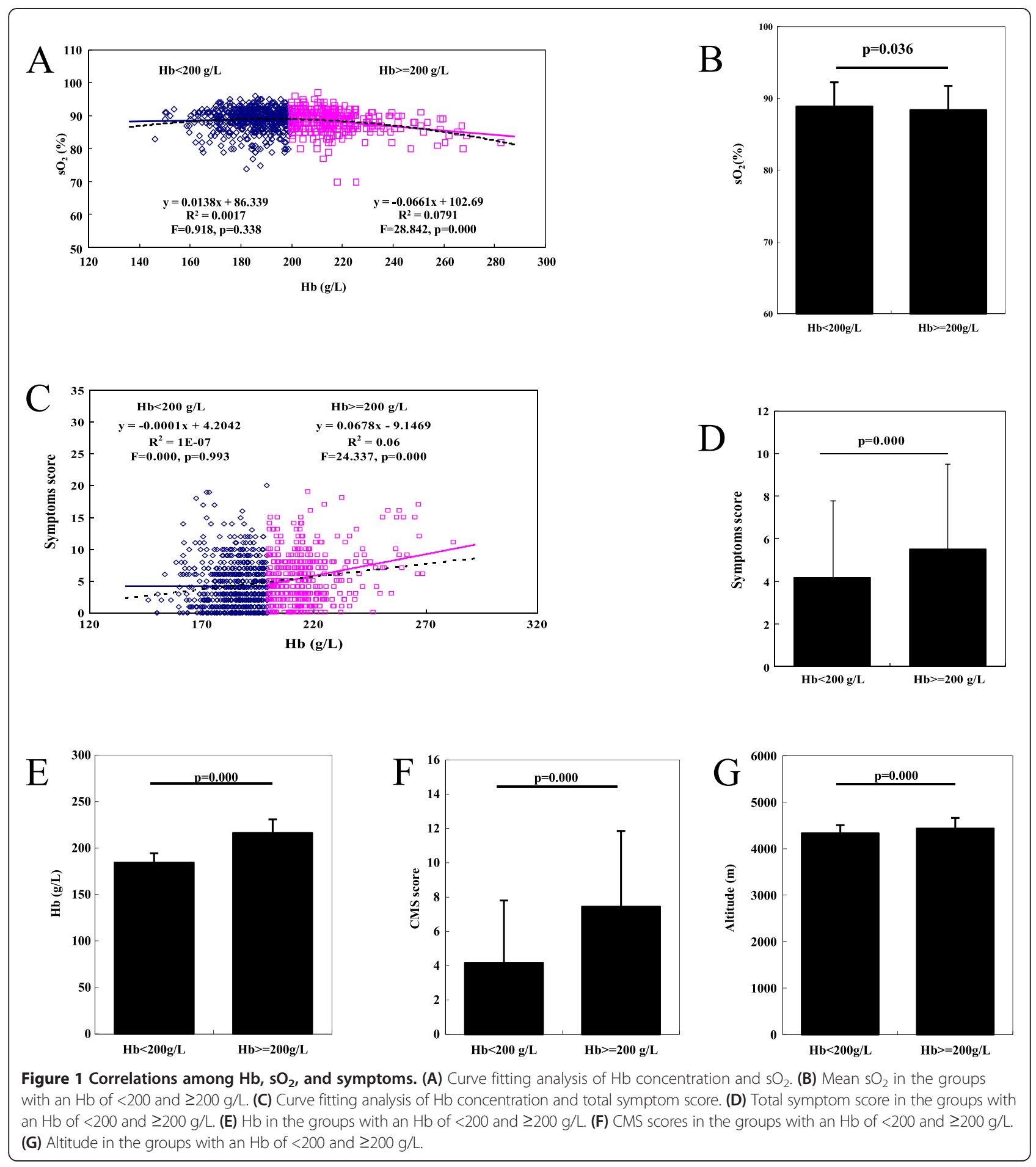

$\geq 210 \mathrm{~g} / \mathrm{L}$ in male patients has been used as the most important criterion for CMS in the published Consensus Statement [9]. We found a discrepancy between CMS symptoms and an excessive $\mathrm{Hb}$ level $(\geq 210 \mathrm{~g} / \mathrm{L})$ in some subjects and characterized the effect patterns of height and length of residence at a high altitude on the $\mathrm{Hb}$ concentration and CMS prevalence.

\section{Debate on $\mathrm{Hb}$ threshold selection}

Several CMS scoring systems have been suggested [18-20] while the $210 \mathrm{~g} / \mathrm{L}$ has mainly been used as the diagnostic criterion for male patients [9]. Previously reported criteria were most often calculated by the mean $\mathrm{Hb}$ concentration plus 2, 3, or 4 times the standard deviation (SD) of the entire population $[18,21]$. A Chinese group selected an 
Table 3 Binary logistic correlation analysis of risk factors for CMS

\begin{tabular}{ccc}
\hline & Score & $\mathbf{p}$ \\
\hline Altitude (meters) & 38.5872 & 0.0000 \\
$\mathrm{sO}_{2}(\%)$ & 25.1352 & 0.0000 \\
Drink & 14.6975 & 0.0001 \\
$\mathrm{Mean} \mathrm{BP}(\mathrm{mmHg})$ & 13.6726 & 0.0002 \\
$\mathrm{BMI}\left(\mathrm{kg} / \mathrm{m}^{2}\right)$ & 11.5360 & 0.0007 \\
Altitude time (months) & 5.2909 & 0.0214 \\
HR (beat/min) & 5.1919 & 0.0227 \\
AMS history & 4.4831 & 0.0342 \\
Smoke & 2.5889 & 0.1076 \\
Disease history & 0.0130 & 0.9092 \\
\hline
\end{tabular}

$\mathrm{Hb}$ threshold of $190 \mathrm{~g} / \mathrm{L}$ (mean plus twice the SD) in Tibetans living at a high altitude as a reference for immigrants [22], designating Tibetans as the best high altitude-adapted population [23]. An $\mathrm{Hb}$ threshold of $200 \mathrm{~g} / \mathrm{L}$ (mean plus 3 times the SD) has also been proposed [17]. Although calculation of the threshold with the mean plus a specific multiple of the SD at sea level is a commonly used method, the Hb concentration increases according to the elevated altitude both physically and pathologically. Individuals with an excessively increased $\mathrm{Hb}$ concentration could "pollute" the Hb distribution among the whole cohort, resulting in an artificial threshold derived from the mean and SD in addition to the subjective selection of the SD. For example, the $\mathrm{Hb}$ concentration was $20.74 \pm 2.18 \mathrm{~g} / \mathrm{dL}$ in men who resided above $4,500 \mathrm{~m}$, and the threshold point was as high as $25.1 \mathrm{~g} / \mathrm{dL}$ using the mean plus twice the SD. The Tibetan threshold is not a good reference because the Tibetans are resistant to CMS and may not be comparable with the Hans and other high-altitude populations [24].
A data-mining analysis technique was introduced in this study to calculate the $\mathrm{Hb}$ threshold based on the "optimal" $\mathrm{Hb}$ concentration concept [25]. When a human ascends to a high altitude, adaptive reactions begin to ameliorate hypoxemia owing to the low oxygen partial pressure of inhaled air. Hypoxemia can upregulate the transcription factor hypoxia inducible factor- 1 and induce a number of hypoxia-inducible genes, including erythropoietin [26]. The release of erythropoietin leads to erythrocytosis and an increase in the $\mathrm{Hb}$ concentration [27] so that the blood is able to carry more oxygen to tissues and cells for utilization. Conversely, excessive erythrocytosis can also increase blood viscosity and slow blood velocity, which may decrease the cardiac output [25] and aggravate arterial hypoxemia, slowing the blood supplication to tissues. This suggests the existence of an "optimal" $\mathrm{Hb}$ concentration; i.e., when the $\mathrm{Hb}$ concentration is below the "optimal" value, physiologic erythrocytosis response helps to elevate ability of blood to transport oxygen. When the $\mathrm{Hb}$ exceeds this optimal value, the erythrocytosis response aggravates the oxygen supplication-demanding imbalance and triggers CMS pathologic processes.

$K$-means clustering is a statistical method used to partition observations into clusters with the nearest means, which serve as prototypes of the clusters. In this study, we were able to completely separate the subjects into two populations ( $\mathrm{Hb}$ of $<200$ and $\geq 200 \mathrm{~g} / \mathrm{L}$ ) using $k$ means clustering analysis; subsequent analyses showed that the 95\% CIs were clearly nonoverlapping. In this sense, the nonoverlapping range can serve as a threshold for the different dynamics of the two populations. When the $\mathrm{Hb}$ level drifts beyond the 95\% CI, further drifting away from the first population will lead to marked changes in the $\mathrm{Hb}-\mathrm{sO}_{2}$ relationship. In the first population $(\mathrm{Hb}<200 \mathrm{~g} / \mathrm{L})$, which represents the physiologic response of erythrocytosis, the $\mathrm{sO}_{2}$ remains stable

Table 4 Variables in the CMS anticipation equation

\begin{tabular}{|c|c|c|c|c|c|c|c|c|c|}
\hline \multirow[t]{3}{*}{ 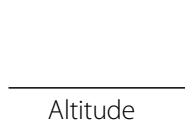 } & \multirow[t]{2}{*}{ B } & \multirow[t]{2}{*}{ S.E. } & \multirow[t]{2}{*}{ Wald } & \multirow[t]{2}{*}{$\mathrm{p}$} & \multirow[t]{2}{*}{$\operatorname{Exp}(B)$} & \multicolumn{2}{|c|}{ 95.0\% C.I. for $\operatorname{EXP(B)}$} & \multirow{2}{*}{$\begin{array}{l}\text { Cox } \& \text { Snell } \\
\text { R Square }\end{array}$} & \multirow{2}{*}{$\begin{array}{c}\text { Nagelkerke } \\
\text { R Square }\end{array}$} \\
\hline & & & & & & Lower & Upper & & \\
\hline & $0.0025^{* *}$ & 0.0005 & 20.6871 & 0.0000 & 1.0025 & 1.0014 & 1.0036 & 0.1811 & 0.2602 \\
\hline Altitude time & $0.0061^{*}$ & 0.0031 & 3.8763 & 0.0490 & 1.0061 & 1.0000 & 1.0123 & & \\
\hline Smoke & -0.0600 & 0.1670 & 0.1311 & 0.7172 & 0.9415 & 0.6974 & 1.3053 & & \\
\hline Drink & $1.0292^{*}$ & 0.2601 & 15.6731 & 0.0000 & 2.7980 & 1.6811 & 4.656 & & \\
\hline $\mathrm{sO}_{2}$ & $-0.1388^{* *}$ & 0.0392 & 12.5181 & 0.0004 & 0.8704 & 0.8059 & 0.9399 & & \\
\hline$H R$ & 0.0019 & 0.0090 & 0.0426 & 0.8364 & 1.0019 & 0.9844 & 1.0196 & & \\
\hline $\mathrm{BMI}$ & 0.0806 & 0.0561 & 2.0610 & 0.1511 & 1.0839 & 0.9710 & 1.2100 & & \\
\hline AMS history & -0.5221 & 0.2714 & 3.7003 & 0.0544 & 0.5933 & 0.3485 & 1.0099 & & \\
\hline Disease history & -0.3839 & 0.3877 & 0.9806 & 0.3221 & 0.6812 & 0.3186 & 1.4564 & & \\
\hline Mean BP & 0.0214 & 0.0123 & 3.0455 & 0.0810 & 1.0216 & 0.9974 & 1.0465 & & \\
\hline Constant & -4.1097 & 4.8249 & 0.7255 & 0.3943 & 0.0164 & & & & \\
\hline
\end{tabular}


Table 5 Model detection of the CMS anticipation equation (binary logistic analysis)

\begin{tabular}{cccccc}
\hline Observed & \multicolumn{2}{c}{ Predicted } & $\begin{array}{c}\text { Percentage } \\
\text { correct }\end{array}$ & $\mathbf{x}^{2}$ & $\mathbf{p}$ \\
\cline { 2 - 5 } & CMS & Non-CMS & & & \\
\hline CMS & 296.0000 & 21.0000 & 93.3754 & 88.3319 & 0.000 \\
Non-CMS & 78.0000 & 47.0000 & 37.6000 & & \\
\multicolumn{2}{c}{ Overall percentage } & 77.6018 & & \\
\hline
\end{tabular}

as $\mathrm{Hb}$ increases; in the second population $(\mathrm{Hb} \geq 200 \mathrm{~g} / \mathrm{L})$, which represents the pathologic response part of erythrocytosis, the $\mathrm{sO}_{2}$ decreases as the $\mathrm{Hb}$ increases. The correlations between $\mathrm{Hb}$ and the symptoms in the two subpopulations further confirm the marked changes in the $\mathrm{Hb}-\mathrm{SO}_{2}$ relationship. Still, more remains to be elucidated regarding the $\mathrm{Hb}$ threshold, such as that in female individuals and native highlanders, including Tibetans and Andeans.

\section{Discrepancy between $\mathrm{Hb}$ concentration and symptoms}

Our data also showed a discrepancy between the $\mathrm{Hb}$ concentration and CMS symptoms. Some subjects had a very high $\mathrm{Hb}$ concentration but could not be classified as patients with CMS because their CMS symptoms were obscure. Excessive erythrocytosis per se represents a threat to humans, sometimes even a lethal threat, because of the risk of development of a thrombus or embolism in vital organs $[28,29]$. If the diagnosis of CMS cannot be made, dangerous health conditions might be disregarded and proper medical treatment will not be rendered. Some individuals with low $\mathrm{Hb}$ concentrations and severe CMS symptoms could not be diagnosed with CMS. Although
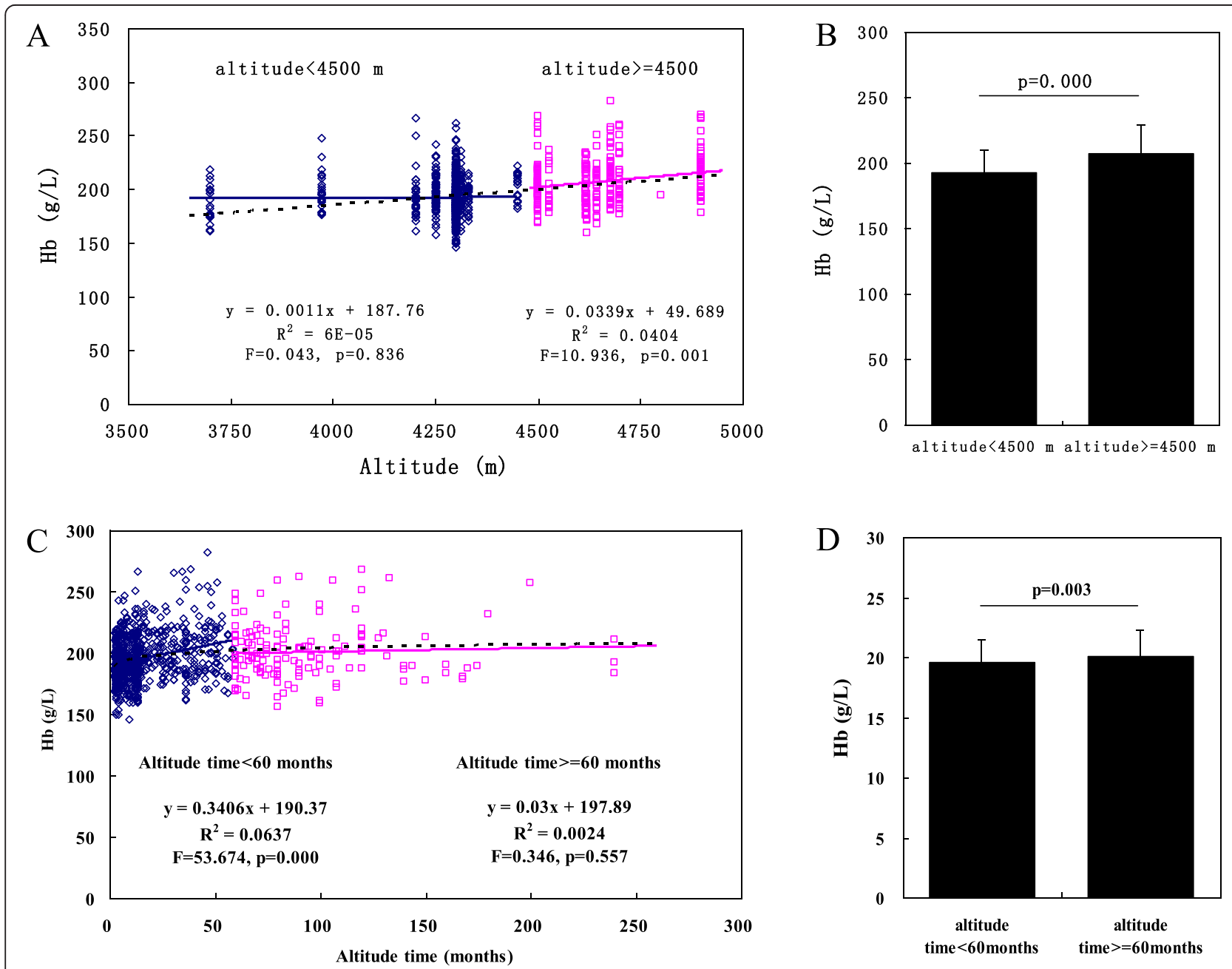

Figure 2 Correlations of $\mathrm{Hb}$, symptom score, and CMS score with altitude and length of residence at high altitude. (A) Curve fitting analysis of $\mathrm{Hb}$ concentration and altitude. (B) $\mathrm{Hb}$ concentration in the groups at an altitude of $<4500$ and $\geq 4500 \mathrm{~m}$. (C) Curve fitting analysis of $\mathrm{Hb}$ concentration and length of exposure to high altitude. (D) $\mathrm{Hb}$ concentration in the groups with a length of exposure to high altitude of $<60$ and $\geq 60$ months. (E) Curve fitting analysis of CMS score and altitude. (F) CMS score in the groups at an altitude of $<4500$ and $\geq 4500 \mathrm{~m}$.

(G) Curve fitting analysis of CMS score and length of exposure to high altitude. $\mathbf{H}$ ) CMS score in the groups with a length of exposure to high altitude of $<60$ and $\geq 60$ months. 
we found significant correlations between the $\mathrm{Hb}$ concentration and each CMS symptom, all were rather weak with the exception of cyanosis (data not shown). Therefore, there may be a low-Hb subtype of CMS that differs from the present subtype characterized by a high $\mathrm{Hb}$ concentration; i.e., Monge's disease or polycythemia. In the high- $\mathrm{Hb}$ subtype, excessive erythrocytosis is the primary risk factor; in the low-Hb subtype, other risk factors such as longterm insufficient oxygen supplication to vital organs are likely to be fundamental causes [30].

CMS was first termed "erythema syndrome of high altitude" [1] before being termed CMS in 1998 [31]. CMS was then further divided into two subtypes: CMS and high-altitude pulmonary hypertension [32]. However, this division was confusing because CMS shares the same term as one of its subtypes. It would be clearer to name this subtype of CMS as characterized by excessive $\mathrm{Hb}$ polycythemia, the original term.

CMS may manifest as high-altitude pulmonary edema in about $1 \%$ of subjects with a low $\mathrm{Hb}$ concentration [24], and these subjects could erroneously be classified as having CMS using the scoring system for diagnosis. Moreover, although CMS (polycythemia) is characterized by excessive erythrocytosis, its importance is weakened or "diluted" by multiple symptoms based on the present diagnostic criteria. The weight of three points for excessive polycythemia is lower than the weight of non-specific symptoms, such as sleep disturbances, headache, and dizziness, which can be found in a large number of pathophysiologic conditions. Individuals with excessive polycythemia, even those with very severe polycythemia, may be missed, and the optimal treatment time before the patient shows CMS symptoms may be missed. Based on the above considerations, we suggest that $\mathrm{Hb}$ should be given greater weight in the scoring system; for example, 6 points should be given for excessive polycythemia.

\section{Impacts of height and length of residence at a high altitude on CMS}

We used binary logistic analysis to investigate the predisposing factors for CMS. Among these factors, we found that the altitude, length of residence at a high altitude, alcohol use, and $\mathrm{sO}_{2}$ were significantly correlated with the prevalence of CMS. We then analyzed the impacts of height and length of residence at a high altitude on CMS.

CMS usually occurs in long-term residents at a high altitude of $>3000 \mathrm{~m}$. In one study, as the altitude increased, the prevalence of CMS increased among Han immigrants in the Qinghai-Tibet plateau (2,980-5,226 m) [17]. However, our data followed this pattern only when the altitude was $\geq 4500 \mathrm{~m}$. The altitude was not associated with the CMS prevalence or erythrocytosis at an altitude of $<4500 \mathrm{~m}$. Thus, a significant number of humans can become well acclimatized to hypoxic conditions at $<4500 \mathrm{~m}$ by maintaining a stable $\mathrm{Hb}$ concentration $(192.5 \pm 17.2 \mathrm{~g} / \mathrm{L})$ below the "optimal" value $(200 \mathrm{~g} / \mathrm{L})$ irrespective of the altitude itself (Figure 2A,B). While the altitude was $\geq 4500 \mathrm{~m}$ and the $\mathrm{Hb}$ concentration was mostly $\geq 200 \mathrm{~g} / \mathrm{L}(207.3 \pm 21.8 \mathrm{~g} / \mathrm{L})$, excessive erythrocytosis can trigger a vicious circle by impairing oxygen delivery and depressing cellular oxygen supplication. Thus, 4,500 $\mathrm{m}$ should be regarded as the threshold altitude for dwelling, above which most humans cannot acclimatize to such a high altitude.

CMS usually requires a specific duration of residence to develop at a high altitude. A Han man can develop CMS in $<1$ year at $5,300 \mathrm{~m}$ ( 2 months in the current study), while others may not show obvious CMS symptoms until they have lived at a high altitude for $\geq 15$ years (30 years in this study) [17]. Some researchers are convinced that the length of exposure to a high altitude is not associated with the prevalence of CMS, whereas altitude, sex, and ethnic background are significant factors influencing the rate of CMS development [14]. Our data definitely suggest that the length of residence at a high altitude is significantly correlated with CMS development, especially within the first 60 months because the $\mathrm{Hb}$ concentration increases rapidly during this time period. As a human being first ascends to high altitude, the body immediately develops hypoxemia, which triggers adaptive responses including hyperventilation, pulmonary hypertension, and an increase in the cardiac output. As time passes and chemosensitivity becomes blunted, the above responses are substituted by erythrocytosis, angiogenesis, and other processes. The erythrocyte and $\mathrm{Hb}$ levels continue to increase to a very high point unless the oxygen demand of the body is met. According to our data, this mainly occurs within 60 months of living at a high altitude. Thereafter, the rate of increase in the $\mathrm{Hb}$ concentration slows down significantly, and the CMS prevalence gradually stabilizes. Therefore, medical examinations should be regularly performed within the first 60 months of residing at a high altitude. Spending the first 60 months at a high altitude without a CMS incident ensures a much lower probability of the subsequent development of CMS.

\section{Conclusions}

The high prevalence of CMS evaluated in this study using the latest approved scoring system [9] suggests that it is more sensitive than previous diagnosis criteria and favors early screening and treatment of patients with CMS. Based on our data, we suggest that the Hb threshold for CMS is $200 \mathrm{~g} / \mathrm{L}$ despite the altitude difference and that $\mathrm{Hb}$ is weighted with $>6$ points in the CMS scoring system. Moreover, an elevation of $>4500 \mathrm{~m}$ and the first 60 months after ascending are two critical factors associated with the 
development of CMS in long-term residents. Regular medical examinations should be performed within the first 60 months of residing at a high altitude, especially $\geq 4500 \mathrm{~m}$, for early screening of CMS. To be noticed, our study was focusing on younger subjects $(24.08 \pm 5.66$ years), which may limit the ability to generalize and compare our results to other data sets. More studies with larger population and from different nations are needed to validate the above findings.

\section{Abbreviations}

AMS: Acute mountain sickness; BMI: Body mass index; CMS: Chronic mountain sickness; $\mathrm{Hb}$ : Hemoglobin; $\mathrm{HR}$ : Heart rate; $\mathrm{sO}_{2}$ : Oxygen saturation.

\section{Competing interests}

The authors declare that they have no competing interests.

\section{Authors' contributions}

$\mathrm{CHJ}$ designed and performed the research, analyzed the data, and wrote the paper. JC, YQG, and WXG designed the research, analyzed the data, and wrote the paper. FYL, YJL, and GX performed the research. HYS analyzed the data. All authors contributed significantly to the research and review of the final results. All authors read and approved the final manuscript.

\section{Acknowledgments}

This work was supported by the National Scientific Foundation of China (81101469 and 30971426), the 973 Program of China (2012CB518201), the National Key Technology R\&D Program of China (2009BA185B01), and the Ministry of Health of China (201002012). The authors are grateful to all of the volunteers who participated in this study. We appreciate valuable suggestions from Dr. Liqun Yu of the School of Medicine at Boston University regarding statistical analysis.

\section{Author details}

${ }^{1}$ Department of Pathophysiology and High Altitude Physiology, College of High Altitude Military Medicine, Third Military Medical University, 30 Gaotanyan Street, Shapingba District, Chongqing 400038, P.R. China. ${ }^{2}$ Key Laboratory of High Altitude Medicine, Ministry of Education, Third Military Medical University, 30 Gaotanyan Street, Shapingba District, Chongqing 400038, P.R. China. ${ }^{3}$ Key Laboratory of High Altitude Medicine, PLA, 30 Gaotanyan Street, Shapingba District, Chongqing 400038, P.R. China. ${ }^{4}$ Department of High Altitude Disease, College of High Altitude Military Medicine, Third Military Medical University, 30 Gaotanyan Street, Shapingba District, Chongqing 400038, P.R. China. ${ }^{5}$ Robert Stone Dow Neurobiology Laboratories, Legacy Research Institute, Portland, OR 97232, USA.

Received: 29 December 2013 Accepted: 3 July 2014

Published: 9 July 2014

\section{References}

1. Monge CC, Whittembury J: Chronic mountain sickness. Johns Hopkins Med J 1976, 139(SUPPL):87-89.

2. Wu TY: Chronic mountain sickness on the Qinghai-Tibetan plateau. Chin Med J (Engl) 2005, 118(2):161-168.

3. Pasha MA, Newman JH: High-altitude disorders: pulmonary hypertension: pulmonary vascular disease: the global perspective. Chest 2010, 137(6 Suppl):13S-19S.

4. Leon-Velarde F, McCullough RG, McCullough RE, Reeves J: Proposal for scoring severity in chronic mountain sickness (CMS). Adv Exp Med Biol 2003, 543:339-354.

5. Groepenhoff H, Overbeek MJ, Mule M, Van der Plas M, Argiento P, Villafuerte FC, Beloka S, Faoro V, Macarlupu JL, Guenard H, de Bisschop C, Martinot JB, Vanderpool R, Penaloza D, Naeije R: Exercise pathophysiology in patients with chronic mountain sickness. Chest 2012, 142(4):877-884.

6. Kong FY, Li Q, Liu SX: Poor sleep quality predicts decreased cognitive function independently of chronic mountain sickness score in young soldiers with polycythemia stationed in Tibet. High Alt Med Biol 2011, 12(3):237-242.
7. Li X, Pei T, Xu H, Tao F, You H, Liu Y, Gao Y: Ecological study of community-level factors associated with chronic mountain sickness in the young male Chinese immigrant population in Tibet. J Epidemiol 2012, 22(2):136-143

8. Pratali L, Rimoldi SF, Rexhaj E, Hutter D, Faita F, Salmon CS, Villena M, Sicari R, Picano E, Allemann Y, Scherrer U, Sartori C: Exercise induces rapid interstitial lung water accumulation in patients with chronic mountain sickness. Chest 2012, 141(4):953-958.

9. Rimoldi SF, Rexhaj E, Pratali L, Bailey DM, Hutter D, Faita F, Salmon CS, Villena M, Nicod P, Allemann Y, Scherrer U, Sartori C: Systemic vascular dysfunction in patients with chronic mountain sickness. Chest 2012, 141(1):139-146.

10. Leon-Velarde F, Maggiorini M, Reeves JT, Aldashev A, Asmus I, Bernardi L, Ge RL, Hackett P, Kobayashi T, Moore LG, Penaloza D, Richalet JP, Roach R, Wu T, Vargas E, Zubieta-Castillo G, Zubieta-Calleja G: Consensus statement on chronic and subacute high altitude diseases. High Alt Med Biol 2005, 6(2):147-157.

11. Gonzales GF, Tapia V, Gasco M, Gonzales-Castaneda C: Serum testosterone levels and score of chronic mountain sickness in Peruvian men natives at $4340 \mathrm{~m}$. Andrologia 2011, 43(3):189-195.

12. Zubieta-Castillo G Sr, Zubieta-Calleja GR Jr, Zubieta-Calleja L: Chronic mountain sickness: the reaction of physical disorders to chronic hypoxia. J Physiol Pharmacol 2006, 57(Suppl 4):431-442.

13. Beall CM, Goldstein MC: Hemoglobin concentration of pastoral nomads permanently resident at 4,850-5,450 meters in Tibet. Am J Phys Anthropol 1987, 73(4):433-438

14. Wu T, Wang X, Wei C, Cheng H, Li Y, Ge D, Zhao H, Young P, Li G, Wang Z Hemoglobin levels in Qinghai-Tibet: different effects of gender for Tibetans vs. Han. J Appl Physiol 2005, 98(2):598-604.

15. Leon-Velarde F, Gamboa A, Chuquiza JA, Esteba WA, Rivera-Chira M, Monge CC: Hematological parameters in high altitude residents living at 4,355, 4,660, and 5,500 meters above sea level. High Alt Med Biol 2000, 1(2):97-104.

16. Okumiya K, Sakamoto R, Kimura Y, Ishine M, Kosaka Y, Wada T, Wada C, Nakatsuka M, Ishimoto Y, Hirosaki M, Kasahara Y, Konno A, Chen W, Fujisawa M, Otsuka K, Nakashima M, Wang H, Dai Q, Yang A, Qiao H, Gao J, Li Z, Zhang Y, Ge RL, Matsubayashi K: Comprehensive geriatric assessment of elderly highlanders in Qinghai, China II: the association of polycythemia with lifestyle-related diseases among the three ethnicities. Geriatr Gerontol Int 2009, 9(4):342-351.

17. Wu T, Li W, Li Y, Ri-Li G, Cheng Q, Wang S, Zhao G, Wei L, Jin Y, Don G: Epidemiology of chronic mountain sickness: ten years' study in Qinghai-Tibet. In Progress in Mountain Medicine and High Altitude Physiology. Edited by Ohno H, Kobayashi T, Masuyama S, Nakashima M. Matsumoto, Japan: Press Committee of the 3rd World Congress on Mountan Medicine and High Altitude Physiology; 1998:120-125.

18. Wu T: Proposal for CMS Guidilines Discussion, CMS Consensus Working group. In VI World Congress on Mountain Medicine and High Altitude Physiology. China: Xining, Qinghai; 2004.

19. Leon-Velarde F: The diagnositic criteria for CMS. In Progress in Mountain Medicine and High Altitude Physiology. Edited by Ohno H, Kobayashi T, Masuyama S, Nakashima M. Matsumoto, Japan: Press Committee of the 3rd World Congress on Mountain Medicine and High Altitude Physiology; 1998:160.

20. Aldashev A: Kyrgyzian Proposal for CMS Guidelines Discussion, CMS Consensus Working Group. In VI World Congress on Mountain Medicine and High Altitude Physiology. China: Xining, Qinghai; 2004.

21. Monge C, Leon-Velarde F, Arregui A: Increasing prevalence of excessive erythrocytosis with age among healthy high-altitude miners. $N$ Engl J Med 1989, 321(18):1271.

22. Wu T, Li W, Wei L, Ri-Li G, Wang S, Cheng Q, Jin Y: A preliminary study on the diagnosis of chronic mountain sickness in Tibetan populations. In Progress in Mountain Medicine and High Altitude Physiology. Edited by Ohno H, Kobayashi T, Masuyama S, Nakashima M. Matsumoto, Japan: Press Committee of the 3rd World Congress on Mountan Medicine and High Altitude Physiology; 1998:337-342.

23. Beall CM: Andean, Tibetan, and Ethiopian patterns of adaptation to highaltitude hypoxia. Integr Comp Biol 2006, 46(1):18-24.

24. Naeije R, Vanderpool R: Pulmonary hypertension and chronic mountain sickness. High Alt Med Biol 2013, 14(2):117-125.

25. Lenfant C, Sullivan K: Adaptation to high altitude. N Engl J Med 1971, 284(23):1298-1309. 
26. Lee FS, Percy MJ: The HIF pathway and erythrocytosis. Annu Rev Pathol 2011, 6:165-192.

27. McMullin MF: HIF pathway mutations and erythrocytosis. Expert Rev Hematol 2010, 3(1):93-101.

28. Venegoni P, Schroth G: Myocardial infarction and polycythemia vera: how should we treat it? Cathet Cardiovasc Diagn 1994, 32(3):259-261.

29. Nand S, Orfei E: Pulmonary hypertension in polycythemia vera. Am J Hematol 1994, 47(3):242-244.

30. Hornbein TF: Long term effects of high altitude on brain function. Int J Sports Med 1992, 13(Suppl 1):S43-S45.

31. Ohno H, Kobayashi T, Masuyama S, Nakashima M: First International Consensus Group Meeting on Chronic Mountain Sickness (CMS) in Matsumoto. In Progress in Mountain Medicine and High Altitude Physiology. Edited by Ohno H, Kobayashi T, Masuyama S, Nakashima M. Matsumoto, Japan: Press Committee of the 3rd World Congress on Mountain Medicine and High Altitude Physiology; 1998:166.

32. Viscor G, Ricar A, Leal C: International Working Group for Chronic Mountain Sickness. In Height: Proceedings of the 5th World Congress on Mountain Medicine and High Altitude Physiology. Edited by Viscor G, Ricar A, Leal C. Barcelona, Spain: Universitat de Barcelona; 2003:39-42.

doi:10.1186/1471-2458-14-701

Cite this article as: Jiang et al:: Chronic mountain sickness in Chinese Han males who migrated to the Qinghai-Tibetan plateau: application and evaluation of diagnostic criteria for chronic mountain sickness. BMC Public Health 2014 14:701.

\section{Submit your next manuscript to BioMed Central and take full advantage of:}

- Convenient online submission

- Thorough peer review

- No space constraints or color figure charges

- Immediate publication on acceptance

- Inclusion in PubMed, CAS, Scopus and Google Scholar

- Research which is freely available for redistribution 